\title{
An assessment of medical students' knowledge of prediabetes and diabetes prevention
}

\author{
Tamkeen Khan * (D), Gregory D. Wozniak and Kate Kirley
}

\begin{abstract}
Background: The United States has 84 million adults with prediabetes, putting them at a higher risk than the general population for developing type 2 diabetes. Missed opportunities among primary care providers in diagnosing and managing patients with prediabetes represent a gap in care, suggesting there is a need to educate practicing physicians and medical students about diabetes prevention. The purpose of this study is to assess medical students' basic knowledge of prediabetes and diabetes prevention, identify potential educational needs, and target areas for improvement in undergraduate medical education curricula.

Methods: A cross-sectional study to assess medical students' preclinical and clinical management knowledge of prediabetes and diabetes prevention. Medical students attending the 2016 American Medical Association's annual meeting took a 6-item knowledge questionnaire using a mobile application or a paper version. Scores were reported for the full sample of respondents, by year in medical school, by topic area, and by mode of survey response.

Results: The average student answered fewer than half of the questionnaire questions correctly. Scores on some items addressing preclinical content were higher among third- and fourth-year students compared to first- and second-year students ( $p=0.039$ and effect size $=0.363$ ). Average scores on the items addressing clinical management were not significantly different by year in medical school, but the item measuring effectiveness of metformin to a lifestyle change program had $41.9 \%$ correct answers among the mobile application respondents compared to $21.5 \%$ among paper test respondents ( $p=0.003$ and effect size $=0.463$ ).

Conclusions: Medical student performance on the prediabetes knowledge questionnaire was low. Students' year in medical school had a slight impact on overall performance, but only for certain questions. The results suggest the need for improvements in current medical school curricula for increasing the awareness of screening for prediabetes as well as the benefits of the lifestyle change programs in the National Diabetes Prevention Program.
\end{abstract}

Keywords: Prediabetes, Diabetes prevention, Physician training, Medical education, Educational measurement

\section{Background}

Nearly 1 in 3 adults in the United States (US) has prediabetes, a condition characterized by blood glucose levels that are elevated- hemoglobin A1C (HbA1c) test results between 5.7 and $6.4 \%$ - but not high enough to be classified as diabetes [1]. Risk factors for prediabetes include family history of type 2 diabetes, history of gestational diabetes, elevated body mass index (BMI), and sedentary lifestyle. Individuals with prediabetes are at higher risk

\footnotetext{
* Correspondence: Tamkeen.Khan@ama-assn.org

Improving Health Outcome, American Medical Association, 330 N. Wabash Avenue, Suite 39300, Chicago, IL 60611, USA
}

than the general population for developing type 2 diabetes, heart disease, stroke, and other serious health conditions [1]. People with prediabetes can reduce their risk of developing type 2 diabetes by participating in structured lifestyle change programs (LCPs). Many LCPs currently available are modeled after the original Diabetes Prevention Program research study focused on promoting healthy diet, weight loss and increased physical activity, and are recognized by the Centers for Disease Control and Prevention's (CDC) National Diabetes Prevention Program (National DPP) [2, 3]. Research showed that participation in an LCP reduced the

(c) The Author(s). 2019 Open Access This article is distributed under the terms of the Creative Commons Attribution 4.0 International License (http://creativecommons.org/licenses/by/4.0/), which permits unrestricted use, distribution, and reproduction in any medium, provided you give appropriate credit to the original author(s) and the source, provide a link to the Creative Commons license, and indicate if changes were made. The Creative Commons Public Domain Dedication waiver (http://creativecommons.org/publicdomain/zero/1.0/) applies to the data made available in this article, unless otherwise stated. 
incidence of type 2 diabetes by $58 \%$ relative to placebo at an average follow-up time of 3 years. In comparison, those treated with metformin had a $31 \%$ reduced 3-year incidence of type 2 diabetes compared to the placebo group [3]. Primary care physicians play a key role in screening, testing, and referring patients with prediabetes to LCPs.

The evidence base for preventing diabetes via intensive lifestyle change is substantial [4-9]. The United States Preventive Services Task Force (USPSTF) incorporated this evidence into the updated recommendation regarding screening for abnormal glucose and type 2 diabetes [10]. The grade B recommendation states that physicians should screen individuals for abnormal glucose if they are between the ages of 40 and 70 and are overweight or obese. USPSTF also recommends that all individuals with abnormal glucose should be referred for intensive behavioral counseling to promote lifestyle change [11]. Despite the evidence supporting intensive LCPs and clinical guidelines encouraging physicians to refer patients to these programs, they are still vastly underutilized and providers' awareness and patient referral rates to LCPs are still low [12-14].

Attitudes towards prediabetes coupled with missed opportunities among these providers in diagnosing and managing prediabetes represent a practice gap [15]. A recent survey determined that primary care physicians have significant knowledge gaps regarding prediabetes screening, diagnosis, and management, with less than $20 \%$ of physicians correctly answering questions in those domains [16]. These practice and knowledge gaps are an area where the American Medical Association (AMA) is focusing efforts towards educating physicians to screen and refer individuals with prediabetes to CDC-recognized LCPs [17]. Given that the practice and knowledge gaps observed by both Mainous et al. and Tseng et al. were so substantial, this begs the question of whether physicians in-training are receiving adequate prediabetesrelated education $[15,16]$.

Limited information is available on whether prediabetes management or diabetes prevention is being taught in undergraduate medical education (UME) curricula. Physicians in training lack confidence in management of diabetes, report a need for further training [18], and often benefit from additional educational interventions and resources [19]. Furthermore, there is no information publicly-available from the National Board of Medical Examiners that describes whether medical students are being assessed on prediabetes or prevention of type 2 diabetes, specifically in the United States Medical Licensing Examination. This study attempts to measure medical students' knowledge of prediabetes and diabetes prevention to identify the potential educational needs and areas for improvement in chronic disease prevention curricula in UME.

\section{Methods}

A 6-item multiple choice questionnaire (Additional file 1) was developed to assess medical students' basic knowledge of prediabetes and type 2 diabetes prevention. The items were designed to reflect common domains typically used to teach disease-specific knowledge to medical students: epidemiology, diagnosis, and management, which included treatment options and clinical guidelines. These survey topic areas align to the key knowledge domains for prediabetes.

We relied on 3 subject-matter experts, including 2 primary care physicians to assess the questionnaire. Their review indicated the knowledge domains were addressed by the items with an appropriate level of difficulty for medical students.

The questionnaire was administered to a convenience sample of medical students attending the AMA's House of Delegates (HOD) meeting on June 11-15, 2016 in Chicago, Illinois during the Medical Student Section (MSS) sessions. To minimize the burden of response the only demographic characteristic collected from the respondents was year in medical school. Respondents entered data into the AMA meeting mobile application (Crowd Compass, Inc.) or a paper form. Participants were provided with an AMA gift bag as an incentive for completing the questionnaire. The University of Illinois Office for the Protection of Research Subjects Institutional Review Board approved the research protocol.

The percentage of participants correctly answering the individual items and average total scores are reported for the full sample and by the two groups of students, first- and second-year students, and thirdand fourth-year students. The questions were further broken into two categories defined according to the timing in which medical students might typically be taught each item: in the preclinical years or clinical years. Preclinical content was focused on epidemiology and diagnosis (proportion of adults with prediabetes, risk factors for prediabetes, and HbA1c levels), while clinical content was focused on the management of prediabetes (USPSTF screening recommendations, abilities of the LCP and metformin to reduce incidence of diabetes, and recommendations for clinically significant weight loss ranges). To explore whether lower performance on specific questions might be explained by timing of exposure to specific content in their curriculum, we assessed differences in performance on preclinical and clinical questions by year in medical school. Differences in scores 
Table 1 Knowledge Questions and Response Frequencies

Preclinical knowledge of prediabetes and diabetes prevention

Response (\%)

Q1. What proportion of adults in the U.S. has prediabetes?
a. 1 in 2
b. 1 in $3^{a}$
c. 1 in 5

48.22

d. 1 in 10

Q2. Which of the following is NOT a risk factor for prediabetes

a. Family history of type 2 diabetes mellitus

b. History of gestational diabetes

c. $B M I$ of $20^{a}$

d. Asian race

e. No answer

Q3. A patient with an $\mathrm{HbA} 1 \mathrm{c}$ of 6.5 has prediabetes?

a. True

73.60

b. False $e^{a}$

26.40

Clinical management knowledge of prediabetes and diabetes prevention

Q4. The 2015 USPSTF recommendation statement about screening for abnormal glucose and type 2 diabetes mellitus recommends screening adults for abnormal glucose if they are:

a. Overweight and obese at any age

b. Age 40 to 70 and overweight or obese $e^{a}$

c. Over the age of 45

d. Over the age of 45 and have at least one additional risk factor for

e. No answer

Q5. Which of the following best describes the abilities of metformin and the National DPP [LCP] to reduce the incidence of type 2 diabetes mellitus among individuals with prediabetes?

a. Neither metformin nor the National Diabetes Prevention Program are

more effective than placebo

b. Both metformin and the National Diabetes Prevention Program are

more effective than placebo, and they are similarly effective to each other

Program (both are better than placebo)

d. The National Diabetes Prevention Program is nearly twice as effective as metformin (both are better than placebo) ${ }^{a}$

e. No answer

Q6. Individuals who participate in the National Diabetes Prevention Program [LCP] can help prevent or delay the onset of type 2 diabetes if they lose a minimum of:

$$
\begin{aligned}
& \text { a. } 5 \text { to } 7 \% \text { of their body weight }{ }^{a} \\
& \text { b. } 10 \text { to } 12 \% \text { of their body weight } \\
& \text { c. } 15 \% \text { of their body weight }
\end{aligned}
$$

Indicates the correct answer

between years of medical education and instrument modality (mobile application versus paper format) were examined using analysis of variance (ANOVA). Statistical significance is presented at both $p<0.05$ and $p<0.10$ since significance levels are a decreasing function of sample size [20, 21]. Effect sizes were also calculated, with an effect size greater than 0.33 used to distinguish differences of practical significance between the means [22]. All analyses were performed in STATA 13 (College Station, TX). 


\section{Results}

There were 600 medical students who attended the meeting; 258 respondents completed the questionnaire; 61 respondents were residents, fellows, or attending physicians who wished to test their knowledge; the remaining 197 current medical students were used in the analysis. The medical students who attended the AMA HOD meeting, represented a total of 138 schools. Among the 197 current medical students, over threequarters $(n=156)$ were first- and second-year students, and the remaining sample $(n=41)$ were third- and fourth-year students.

The question items and response frequencies are shown in Table 1. Among all respondents, almost $60 \%$ correctly answered the question about the optimal weight loss range for preventing or delaying the onset of type 2 diabetes. On the other hand, only 13\% responded correctly to the question about the USPSTF recommendations for screening. Roughly half the respondents answered questions about prediabetes prevalence and risk factors correctly, and slightly more than a quarter of the respondents correctly answered questions about prediabetes diagnosis and interventions to prevent diabetes.

The percentage of correct responses by item and year in medical school are shown in Table 2. When separated by years in medical school, almost $40 \%$ of the third- and fourth-year students correctly responded to the question about HbA1c levels, while fewer than one-quarter of the first- and second-year students answered correctly ( $p=$ 0.039 and effect size $=0.363$ ). Table 3 shows that the overall mean scores for the preclinical items were higher than the scores for the clinical management questions. Although some preclinical items demonstrated a trend towards better performance for third- and fourth-year students, their scores were not statistically different from first- and second-year students. Mode of response scores are shown in Table 4 , where almost $60 \%$ of the students who took the test on paper responded correctly to the preclinical question regarding prediabetes risk factors, compared to $40 \%$ of electronic mobile respondents $(p=$ 0.013 and effect size $=0.385$ ). Interestingly slightly over $40 \%$ of electronic respondents correctly answered the clinical item comparing the effectiveness of metformin versus $\mathrm{LCP}$, relative to a little over $20 \%$ of the paper respondents $(p=0.003$ and effect size $=0.463)$. Clinical management scores were lower for those who took the test on paper $(p=0.048)$ compared to those who took the test using the mobile application, however the effect size was small at 0.078 as shown in Table 5 .

\section{Discussion}

The results suggest that medical students' overall knowledge of preclinical and clinical management of prediabetes and diabetes prevention was poor. The average student respondent failed to answer more than one-half of the questions correctly. The questions with the lowest scores, where less than one-third of the respondents answered correctly, were related to knowledge of USPSTF recommendations, HbA1c levels for prediabetes diagnosis, and the effectiveness of metformin and the LCP to reduce the incidence of type 2 diabetes. The year in medical school had a relatively small impact on overall performance, affecting only the questions regarding HbA1c levels and prediabetes risk factors for first- and second-year students versus those in their third- and fourth-year.

Prediabetes knowledge and practice gaps that exist among practicing physicians might be partially explained

Table 2 Percentage of Participants Correctly Answering Prediabetes and Diabetes Prevention Knowledge Questions, by Year in Medical School

\begin{tabular}{|c|c|c|c|c|}
\hline & $\begin{array}{l}\text { All Students } \\
(n=197)\end{array}$ & $\begin{array}{l}\text { 1st \& 2nd year Students } \\
(n=156)\end{array}$ & $\begin{array}{l}\text { 3rd \& 4th year Students } \\
(n=41)\end{array}$ & $\begin{array}{l}p \text {-value } \\
\text { [effect size] }\end{array}$ \\
\hline \multicolumn{5}{|c|}{ Preclinical knowledge of prediabetes and diabetes prevention } \\
\hline Q1. Proportion of adults with prediabetes & 48.22 & 50.00 & 41.46 & $\begin{array}{l}0.333 \\
{[0.170]}\end{array}$ \\
\hline Q2. Prediabetes risk factors & 53.30 & 50.00 & 65.85 & $\begin{array}{l}0.071^{*} \\
{[0.320]}\end{array}$ \\
\hline Q3. HbA1c levels & 26.4 & 23.08 & 39.02 & $\begin{array}{l}0.039^{* *} \\
{[0.363]}\end{array}$ \\
\hline \multicolumn{5}{|c|}{ Clinical management knowledge of prediabetes and diabetes prevention } \\
\hline Q4. USPSTF recommendations & 12.69 & 12.18 & 14.63 & $\begin{array}{l}0.677 \\
{[0.072]}\end{array}$ \\
\hline Q5. Metformin vs LCP & 27.92 & 27.56 & 29.27 & $\begin{array}{l}0.830 \\
{[0.038]}\end{array}$ \\
\hline Q6. National DPP weight loss & 58.88 & 59.62 & 56.10 & $\begin{array}{l}0.686 \\
{[0.071]}\end{array}$ \\
\hline
\end{tabular}

$p$-values student scores are significantly different from 1 st $\& 2$ nd year students compared to 3 rd $\& 4$ th year students; ${ }^{*} p<0.10 ;{ }^{* *} p<0.05$; significant effect size for educational research is $\geq 0.33$ 
Table 3 Mean Preclinical and Clinical Scores by Year in Medical School (Maximum Score 3.0)

\begin{tabular}{lllll}
\hline & $\begin{array}{l}\text { All } \\
\text { Students } \\
(n=197)\end{array}$ & $\begin{array}{l}\text { 1st \& 2nd year } \\
\text { Students } \\
(n=156)\end{array}$ & $\begin{array}{l}\text { 3rd \& 4th year } \\
\text { Students } \\
(n=41)\end{array}$ & $\begin{array}{l}p \text {-value } \\
\text { [effect } \\
\text { size] }\end{array}$ \\
\hline $\begin{array}{l}\text { Preclinical knowledge of prediabetes and diabetes prevention } \\
\text { Clinical management knowledge of prediabetes and diabetes }\end{array}$ & 1.28 & 1.23 & 1.46 & $\begin{array}{l}0.114 \\
{[0.275]}\end{array}$ \\
$\begin{array}{l}\text { prevention } \\
\text { P. }\end{array}$ & 0.99 & 0.99 & 1.00 & $\begin{array}{l}0.960 \\
{[0.014]}\end{array}$ \\
\hline
\end{tabular}

$p$-values student scores are significantly different from 1 st \& 2 nd year students compared to 3 rd \& 4th year students; significant effect size for educational research is $\geq 0.33$

by inadequate training received by medical students. Inclusion of prediabetes content in UME curricula is the first step towards addressing these gaps. Prediabetes education in medical school should include content regarding clinical guidelines for screening and diagnosing prediabetes as well evidence-based recommendations for managing prediabetes. This content should be addressed in preclinical education, then reinforced and practiced in clinical experiences.

While there is an opportunity to improve students' knowledge in all domains assessed in this study, the largest knowledge gaps were in clinical management of patients with prediabetes. Given the large volume of patients with prediabetes that the average medical student might be expected to encounter during their UME experience (roughly one-third of adults), there should be many opportunities to expose students to evidence-based management of patients with prediabetes, particularly during their primary care clerkships. However, the knowledge and practice gaps observed in practicing physicians highlight the need for associated faculty development on prediabetes management so that clinical preceptors reinforce these concepts, and to ensure that students can observe and participate in high quality preventive care during their clinical experiences. Faculty development coupled with updated prediabetes-related UME curricula are important steps that medical schools could consider helping address the growing type 2 diabetes epidemic.

A limitation of the study is that the medical students who completed the questionnaire are comprised of students attending the 2016 AMA HOD meeting who volunteered to participate. These students are AMA members and may not be a representative sample of US medical students. However, we are not aware of any evidence suggesting that the convenience sample of students who are members of the AMA would be more or less knowledgeable of preclinical and clinical management of prediabetes and diabetes prevention than medical students who are not AMA members. Next, the questionnaire response rate was 33\% (197/596) when accounting for all medical students in attendance at the meeting. However, the total number of medical students attending the MSS sessions at times that questionnaires were administered was not measured, suggesting the actual response rate may be higher than reported. There also may be a positive response bias and overestimation of average knowledge levels if students who believed they knew more about the topic were more likely to

Table 4 Percentage of Participants Correctly Answering Prediabetes and Diabetes Prevention Knowledge Questions, by Mode of Response

\begin{tabular}{|c|c|c|c|c|}
\hline & $\begin{array}{l}\text { All Students } \\
(n=197)\end{array}$ & $\begin{array}{l}\text { Paper } \\
(n=135)\end{array}$ & $\begin{array}{l}\text { Electronic } \\
(n=62)\end{array}$ & $\begin{array}{l}p \text {-value } \\
\text { [effect size] }\end{array}$ \\
\hline \multicolumn{5}{|c|}{ Preclinical knowledge of prediabetes and diabetes prevention } \\
\hline Q1. Proportion of adults with prediabetes & 48.22 & 48.15 & 48.39 & $\begin{array}{l}0.975 \\
{[0.006]}\end{array}$ \\
\hline Q2. Prediabetes risk factors & 53.30 & 59.26 & 40.32 & $\begin{array}{l}0.013^{* *} \\
{[0.385]}\end{array}$ \\
\hline Q3. HbA1c levels & 26.4 & 25.19 & 29.03 & $\begin{array}{l}0.572 \\
{[0.086]}\end{array}$ \\
\hline \multicolumn{5}{|c|}{ Clinical management knowledge of prediabetes and diabetes prevention } \\
\hline Q4. USPSTF recommendations & 12.69 & 14.07 & 9.68 & $\begin{array}{l}0.392 \\
{[0.132]}\end{array}$ \\
\hline Q5. Metformin vs LCP & 27.92 & 21.48 & 41.94 & $\begin{array}{l}0.003^{* * *} \\
{[0.463]}\end{array}$ \\
\hline Q6. National DPP weight loss & 58.88 & 57.04 & 62.90 & $\begin{array}{l}0.440 \\
{[0.119]}\end{array}$ \\
\hline
\end{tabular}


Table 5 Mean Preclinical and Clinical Scores by by Mode of Response (Maximum Score 3.0)

\begin{tabular}{|c|c|c|c|c|}
\hline & $\begin{array}{l}\text { All Students } \\
(n=197)\end{array}$ & $\begin{array}{l}\text { Paper } \\
(n=135)\end{array}$ & $\begin{array}{l}\text { Electronic } \\
(n=62)\end{array}$ & $\begin{array}{l}p \text {-value } \\
\text { [effect size] }\end{array}$ \\
\hline Preclinical knowledge of prediabetes and diabetes prevention & 1.28 & 1.18 & 1.33 & $\begin{array}{l}0.249 \\
{[0.209]}\end{array}$ \\
\hline Clinical management knowledge of prediabetes and diabetes prevention & 0.99 & 0.93 & 1.15 & $\begin{array}{l}0.048^{* *} \\
{[0.178]}\end{array}$ \\
\hline
\end{tabular}

$p$-values student scores are significantly different from students who took the test electronically compared to students who took the test on paper; ${ }^{* *} p<0.05$; significant effect size for educational research is $\geq 0.33$

complete the questionnaire. The results suggest there is little if any upward bias in knowledge due to these factors. Additionally, the questionnaire was not validated prior to administration to these students. The results from this phase of research can aid the development of a reliable and valid prediabetes knowledge test, similar to those developed and validated for diabetes [23].

\section{Conclusions}

This study, using a questionnaire administered at the AMA's 2016 HOD meeting, highlighted the low medical student performance on prediabetes knowledge. The average student answered fewer than half of the questionnaire questions correctly. Overall performance varied slightly by the students' year in medical school, but only for certain questions between first- and second-year versus third- and fourth- year students. The results suggest a need for a review of current undergraduate medical school curricula, and for potential improvements to increase the awareness of screening for prediabetes as well the benefits of the LCPs that are part of the National DPP.

\section{Additional file}

Additional file 1: Prediabetes Survey. (DOCX $50 \mathrm{~kb}$ )

\section{Abbreviations \\ AMA: American Medical Association; ANOVA: Analysis of Variance; BMI: Body mass index; CDC: Centers for Disease Control and Prevention; HbA1c: Hemoglobin A1c; HOD: House of Delegates; LCP: Lifestyle Change Program; MSS: Medical Student Section; National DPP: National Diabetes Prevention Program; UME: Undergraduate Medical Education; US: United States; USPSTF: United States Preventative Services Task Force}

\section{Acknowledgements}

The authors would like to thank the members of the AMA Improving Health Outcomes team who assisted with administering the questionnaire at the AMA annual Meeting. In addition, the authors would like to acknowledge the contributions of Annalynn Skipper for her review of the manuscript. The findings and conclusions in this report are those of the authors and do not necessarily represent the official position of the AMA.

\section{Authors' contributions}

KK and GW conceived the design of the study. TK and KK developed the questionnaire. KK administered the questionnaire and TK was involved in the data cleaning. All authors were involved in developing the methodology, conducting the statistical analysis, and writing the manuscript. All authors read and approved the final manuscript.

\section{Funding}

None.

\section{Availability of data and materials}

The datasets generated and analyzed during the current study are not available for public use and may be made available from the corresponding author on reasonable request.

\section{Ethics approval and consent to participate}

The study was determined to be exempt from IRB review by the University of Illinois Office for the Protection of Research Subjects Institutional Review Board (Research Protocol \# 2016-0518). An information sheet describing the study was provided for review prior to participating in the survey. Consent to participate was implied by participant completion of the survey. The IRB reviewed this procedure and the content of the information sheet in our claim of exemption submission.

\section{Consent for publication}

Not applicable.

\section{Competing interests}

The authors declare that they have no competing interests.

Received: 8 January 2019 Accepted: 22 July 2019

Published online: 29 July 2019

\section{References}

1. Centers for Disease Control and Prevention. National diabetes statistics report, 2017. Atlanta, GA: Centers for disease control and Prevention; 2017.

2. Albright AL, Gregg EW. Preventing type 2 diabetes in communities across the US: the National Diabetes Prevention Program. Am J Prev Med. 2013; 44(4):S346-51.

3. Knowler WC, Barrett-Connor E, Fowler SE, Hamman RF, Lachin JM, Walker EA, et al. Reduction in the incidence of type 2 diabetes with lifestyle intervention or metformin. N Engl J Med. 2002;346(6):393-403.

4. Ackermann RT, Finch EA, Brizendine E, Zhou H, Marrero DG. Translating the diabetes prevention program into the community: the DEPLOY pilot study. Am J Prev Med. 2008;35(4):357-63.

5. Moin T, Damschroder L, AuYoung M, Maciejewski ML, Datta SK, Weinreb JE, et al. Diabetes prevention program translation in the veterans health administration. Am J Prev Med. 2017;53(1):70-7.

6. Islam NS, Zanowiak JM, Wyatt LC, Chun K, Lee L, Kwon SC, et al. A randomized-controlled, pilot intervention on diabetes prevention and healthy lifestyles in the new York City Korean community. J Community Health. 2013;38(6):1030-41.

7. Townsend CKM, Miyamoto RES, Antonio M, Zhang G, Paloma D, Basques D, et al. The PILI@ work program: a translation of the diabetes prevention program to native Hawaiian-serving worksites in Hawai 'i. Transl Behav Med. 2016;6(2):190-201.

8. Amundson HA, Butcher MK, Gohdes D, TO H, Harwell TS, Helgerson SD, et al. Translating the diabetes prevention program into practice in the general community. Diabetes Educ. 2009;35(2):209-23.

9. Whittemore R, Rosenberg A, Gilmore L, Withey M, Breault A. Implementation of a diabetes prevention program in public housing communities. Public Health Nurs. 2014:31(4):317-26.

10. Siu AL. Screening for abnormal blood glucose and type 2 diabetes mellitus: US preventive services task force recommendation statement. Ann Intern Med. 2015;163(11):861-8. 
11. U.S. Preventative Services Task Force. Abnormal blood glucose and type 2 diabetes mellitus screening [Internet]. 2015 [cited 2011 Jun 20]. Available from: https:/www.uspreventiveservicestaskforce.org/Page/Document/ RecommendationStatementFinal/screening-for-abnormal-blood-glucose-and -type-2-diabetes

12. Schmittdiel JA, Adams SR, Segal J, Griffin MR, Roumie CL, Ohnsorg K, et al. Novel use and utility of integrated electronic health records to assess rates of prediabetes recognition and treatment: brief report from an integrated electronic health records pilot study. Diabetes Care. 2014;37(2):565-8.

13. Mainous AG, Tanner RJ, Baker R. Prediabetes diagnosis and treatment in primary care. J Am Board Family Med. 2016;29(2):283-5.

14. Nhim K, Khan T, Gruss SM, Wozniak G, Kirley K, Schumacher P, et al. Primary care providers' prediabetes screening, testing, and referral behaviors. Am J Prev Med. 2018;55(2):e39-47.

15. Mainous AG, Tanner RJ, Scuderi CB, Porter M, Carek PJ. Prediabetes screening and treatment in diabetes prevention: the impact of physician attitudes. J Am Board Family Med. 2016;29(6):663-71.

16. Tseng E, Greer RC, O'Rourke P, Yeh H-C, McGuire MM, Clark JM, et al. Survey of primary care providers' knowledge of screening for, diagnosing and managing prediabetes. J Gen Intern Med. 2017;32(11):1172-8.

17. American Medical Association, Centers for Disease Control and Prevention Prevent Diabetes STAT [Internet] 2015 [cited 2016 Feb 1]. Available from: http://www.ama-assn.org/sub/prevent-diabetes-stat/for-health-careprofessionals.html

18. George JT, Warriner D, McGrane DJ, Rozario KS, Price HC, Wilmot EG, Kar P, Stratton IM, Jude EB, McKay GA. Lack of confidence among trainee doctors in the management of diabetes: the trainees own perception of delivery of care (TOPDOC) diabetes study. QJM: Int J Med. 2011;104(9):761-6.

19. MacEwen AW, Carty DM, McConnachie A, McKay GA, Boyle JG. A "diabetes acute care day" for medical students increases their knowledge and confidence of diabetes care: a pilot study. BMC Med Educ. 2016;16(1):88

20. Wooldridge JM. Introductory econometrics: a modern appraoch, 3rd edition. Mason, OH. Thomson South-Western, 2006.

21. Leamer EE. Specification searches: ad hoc inference with nonexperimental data. New York: Wiley; 1978.

22. Isaac S, Michael WB. Handbook in research and evaluation: a collection of principles, methods, and strategies useful in the planning, design, and evaluation of studies in education and the behavioral sciences. 1995.

23. Fitzgerald JT, Funnell MM, Anderson RM, Nwankwo R, Stansfield RB, Piatt GA. Validation of the revised brief diabetes knowledge test (DKT2). Diabetes Educ. 2016;42(2):178-87.

\section{Publisher's Note}

Springer Nature remains neutral with regard to jurisdictional claims in published maps and institutional affiliations.

Ready to submit your research? Choose BMC and benefit from:

- fast, convenient online submission

- thorough peer review by experienced researchers in your field

- rapid publication on acceptance

- support for research data, including large and complex data types

- gold Open Access which fosters wider collaboration and increased citations

- maximum visibility for your research: over $100 \mathrm{M}$ website views per year

At $\mathrm{BMC}$, research is always in progress.

Learn more biomedcentral.com/submissions 